\title{
A prospective study of the risk of developing multiple sclerosis in optic neuritis in a tropical and sub-tropical
}

\section{area}

\author{
PJ LANDY \\ From the Department of Neurology, Princess Alexandra Hospital, South Brisbane, Australia
}

SUMMARY 110 cases of optic neuritis were prospectively studied. $62(56 \%)$ developed multiple sclerosis, 13 were lost to survey. However, eight of these had recurrent episodes of optic neuritis. If recurrent episodes of optic neuritis are accorded the same significance as demyelination elsewhere in the CNS, then the incidence of multiple sclerosis in the series rose to $71 \%$, similar to that predicted on an actuarial basis.

Optic nerve demyelination occurs at some stage in the course of multiple sclerosis in almost every patient. ${ }^{1}$ However, the risk reported in the literature of patients with optic neuritis developing multiple sclerosis varies widely. Kurland $e \mathrm{al}^{2}$ placed the percentage at $11.5 \%$, whereas $\mathrm{Lynn}^{3}$ and McAlpine found that $85 \%$ of optic neuritis cases developed multiple sclerosis. These studies were retrospective. In a prospective study of sixty-one cases Sandberg Wollheims found $27 \%$ of cases developed multiple sclerosis and Cohen et al followed sixty cases of optic neuritis and found $28 \%$ later developed multiple sclerosis. There is a wide variance in the series reported from the United States and those of European studies, and the possibility of some geographical basis arises.

\section{Methods}

Between 1953 and 1982 the author saw one-hundredand-ten cases of optic neuritis in three hospitals as a visiting neurologist, or in private practice-the majority being referred by ophthalmologists. The cases selected had no previous history or evidence of demyelination elsewhere in the central nervous system. There was no history of heavy

Address for reprint requests: Dr PJ Landy, Alexandra, 201 Wickham Terrace, Brisbane 4000, Australia.

Received 29 September 1982 and in revised form 28 February 1983. Accepted 4 March 1983. alcohol intake, smoking, or a family history of visual failure. Examination revealed no evidence of retinal disease and no evidence of hypertension, (blood pressure 160/ $100 \mathrm{mmHg}$, or greater).

The clinical syndrome of optic neuritis was defined as a rapid loss of vision associated with a central or paracentral scotoma with a good prognosis for the recovery of vision. In the differential diagnosis of the condition, central serous retinopathy, neurosyphilis, toxic optic atrophy, ischaemic optic neuritis, optic nerve glioma and optic nerve compression had all been considered. While many of these cases were seen before the development of evoked visual responses, all were tested with the Ishiara charts to determine if the non-affected eye had any evidence of involvement. The cases were followed over a prolonged period to determine how many developed multiple sclerosis and if any identifiable factors could be determined. The sex, age of onset, the number of attacks of optic neuritis, and the interval to the development of multiple sclerosis were assessed, and more recently HLA antigen studies and evoked visual responses were performed. The follow-up was by letter and then interview, and where letters were returned unclaimed, a search of the State Electoral Rolls was made to see if the patient was still residing in the State.

\section{Results}

In 110 cases there were 68 females and 42 males, confirming the preponderance of females. The age of onset ranged between 10 and 50 years with the major group between 20 and 41 years.

The place of birth of the patients was as follows: North of the Tropic of Capricorn 13, Tropic of Cap- 
ricorn to latitude $30^{\circ} 71$, other areas of New South Wales below latitude $30^{\circ} 6$, Victoria 4 , New Zealand 1, England 4, Scotland 3, Ireland 2, Holland 2, Germany 2, Finland 1, Poland 1. This shows that the majority of patients were born between the Tropic of Capricorn and latitude $30^{\circ}$.

The place of onset of the optic neuritis was north of the Tropic of Capricorn 6, Tropic of Capricorn to latitude $30^{\circ} 102$, Korea 1 , Germany 1 , the majority (102) again being between the Tropic of Capricorn and latitude $30^{\circ}$. The two patients who had their onset outside Australia were seen within one week of their symptoms becoming manifest.

The eye first affected was the left in 56 cases, and the right in 54. In eight cases both eyes were affected within 24 hours, and of these, three cases went on to develop evidence of demyelination in areas of the nervous system other than the optic nerves. Thirty-two cases had recurrent episodes of optic neuritis; five in the same eye and 27 in the other eye. Of this group of forty cases with recurrent optic neuritis and simultaneous bilateral optic neuritis, 23 went on to develop demyelination elsewhere in the central nervous system. Sixty-two cases developed evidence of demyelination elsewhere in the central nervous system and were regarded as definite multiple sclerosis. Of these 24 were males and 38 females. If, however, recurrent optic neuritis is included with those cases developing multiple sclerosis, then the number rises to 79 .

The interval to the development of multiple sclerosis is plotted in fig 1 . The majority of cases developed evidence of multiple sclerosis within two years.

Thirteen cases were lost to survey which was defined as failure to reply to a registered letter and a

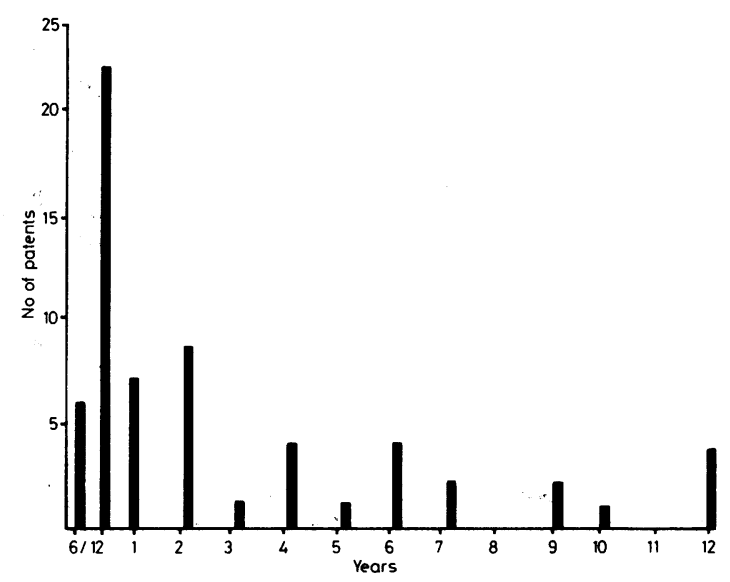

Fig 1 Interval between occurrence of optic neuritis and development of other manifestations of multiple sclerosis.
Table Length of follow-up of 35 cases. No evidence of demyelination elsewhere in the central nervous system.

\begin{tabular}{llll}
\hline $\begin{array}{l}\text { Duration of } \\
\text { follow-up (yr) }\end{array}$ & $\begin{array}{l}\text { No of } \\
\text { patients }\end{array}$ & $\begin{array}{l}\text { Duration of } \\
\text { follow-up (yr) }\end{array}$ & $\begin{array}{l}\text { No of } \\
\text { patients }\end{array}$ \\
\hline 1 & 3 & 14 & 2 \\
2 & 1 & 15 & 2 \\
3 & 1 & 16 & 1 \\
4 & 2 & 17 & 1 \\
5 & 3 & 18 & 2 \\
7 & 4 & 20 & 2 \\
10 & 2 & 22 & 1 \\
11 & 5 & 26 & 1 \\
13 & 2 & & \\
\hline
\end{tabular}

search of the Rolls revealed that they no longer resided in the State. Eight of these cases had manifested episodes of recurrent optic neuritis. Of the 35 cases who showed no evidence of demyelination elsewhere in the central nervous system, including some cases who had recurrent episodes of optic neuritis, the follow-up was over the period as outlined in the table. One of these patients who has been followed up for twenty-six years had his second episode of optic neuritis in the contralateral eye twenty-five years after the first episode. He still showed no evidence of demyelination elsewhere in the central nervous system.

\section{Discussion}

The diagnosis of multiple sclerosis is presumptive when, in a patient with a compatible history and without evidence of any other cause, there is objective evidence of a lesion at another necessarily distinct site in the central nervous system. ${ }^{7} 62 \%$ of patients with optic neuritis were females. Bradley \& Whitty ${ }^{8}$ reported two thirds of their patients were females. $76 \%$ of the patients were born in either tropical or sub-tropical areas of Queensland and Northern New South Wales. Of those who had been born in Australia and suffered an episode of optic neuritis, five had spent two years or more in England, two had been in New Guinea and two exservicemen had served in the South Pacific area during the 1939-45 war. All those who had been outside Australia had travelled after their twentieth birthday. Of the two patients who had their onset of optic neuritis outside Australia one was an exserviceman in Korea and was seen a week after the onset of his optic neuritis, when he was flown back to Brisbane. The other was seen when she returned from an overseas trip two weeks after onset. Sixtytwo cases or $56 \%$ of cases of optic neuritis developed evidence of demyelination elsewhere in the central nervous system. This compares with $28 \%$ in the prospective study of Cohen, Lessell \& Wolf ${ }^{6}$ and the retrospective studies of Rose ${ }^{9}$ where $55 \%$ of 
the cases were found to develop multiple sclerosis, and Lynn ${ }^{3}$ and McAlpine ${ }^{4}$ where $85 \%$ developed multiple sclerosis in their retrospective survey. However, if recurrent attacks of optic neuritis are considered as having the same significance as episodes of demyelination occurring elsewhere in the central nervous system in a patient with a previous attack of optic neuritis, ${ }^{10}$ then the incidence of multiple sclerosis among the cases studied rises to 79-71\%. This corresponds with the suggestion made by Hutchinson ${ }^{11}$ that if the life table method of computing risk is used to overcome the difficulty of varying follow-up periods in individual cases in a series, the risk rises to $78 \%$. The interval between the occurrence of optic neuritis and development of evidence of demyelination elsewhere in the central nervous system other than the optic pathways showed that in six cases there was simultaneous onset of symptoms and signs. Forty-four patients had evidence of demyelination elsewhere within the central nervous system within two years of the onset of optic neuritis-that is $71 \%$ of all cases who subsequently went on to develop definite multiple sclerosis. Bradley \& Whitty ${ }^{8}$ found that the majority of their cases developed evidence of demyelination within four years of the onset of the optic neuritis. McAlpine ${ }^{12}$ however, states that the longer the cases are followed up the higher would be the percentage of cases of optic neuritis which developed signs of multiple sclerosis. Four cases developed their first signs of demyelination twelve years after the onset of their optic neuritis. In a series of 325 cases of multiple sclerosis studied by the author over the years 1953-1982, 106 cases developed clinical signs of optic neuritis or had a history of optic neuritis. In one case the episode of optic neuritis had occurred twenty-seven years before the next episode of demyelination. One of the patients with optic neuritis, who showed no evidence of demyelination elsewhere in the central nervous system, had a second episode in the contralateral eye twenty-five years after the first attack.

\section{Conclusions}

The risk of developing multiple sclerosis in patients suffering from optic neuritis in tropical and subtropical areas of Queensland and northern New South Wales is similar to that in temperate climates overseas. The majority of patients will develop multiple sclerosis. The signs of multiple sclerosis will usually become manifest in the first 2 years after the first attack of optic neuritis, and careful neurological examination of the patient should be conducted during this period.

If the significance of recurrent optic neuritis is the same as demyelination elsewhere in the central nervous system, then the incidence of multiple sclerosis in this series rose to $71 \%$, similar to that which could be projected on an actuarial basis.

\section{References}

1 Lumsden CE. The neuropathology of multiple sclerosis. In: Finker P, Bruyn G, eds. Handbook of Clinical Neurology Vol. 9, (Finker \& Bruyn), Amsterdam, North Holland, 1970.

${ }^{2}$ Kurland LT, Auth TLB, Beebe GW et al. Studies of the Natural History of Multiple Sclerosis. Trans Am Neurol Assoc 1963;88:233-5.

${ }^{3}$ Lynn BH. Retrobulbar Neuritis. Trans Ophthalmol Soc (UK) 1959;79:701-6.

4 McAlpine D. Benign form of multiple sclerosis; results of a long term study. Br Med J 1964;2:1029-32.

5 Sandberg-Wollheim M. Optic neuritis, studies on CSF in relation to clinical course on 61 patients. Acta Neurol Scand 1975;52:167-78.

- Cohen M, Lessell S, Wolf P. Neurology (Minneap) 1979;29:208-13.

${ }^{7}$ McDonald WI. Br J Hosp Med 1977;18:43-8.

${ }^{8}$ Bradley WR, Whitty CWM. Acute optic neuritis, prognosis for the development of multiple sclerosis. $J$ Neurol Neurosurgery Psychiatry 1968;31:10-18.

${ }^{9}$ Rose FC. The etiology of optic neuritis. Clin Sci 1970;39:17.

${ }^{10}$ Compston DAS, Bachelor JR, Earl CJ, McDonald WI. Factors influencing the risk of multiple sclerosis developing in patients with optic neuritis. Brain 1978;101:495-512.

"Hutchinson WM. Acute optic neuritis and the prognosis for multiple sclerosis. J Neurol Neurosurgery Psychiatry 1976;39:283-9.

12 McAlpine $D$. The benign form of multiple sclerosis. Brain 1961,84:186-203. 